\title{
0 arrependido colaborador: uma nova exigência no (ainda) Admirável Mundo Novo
}

https://doi.org/10.21814/uminho.ed.30.3

\author{
Ana Raquel Conceição \\ Professora Convidada equiparada a Professora Auxiliar, na EDUM;
}

Professora Auxiliar no ISMAI

\section{Introdução}

0 presente trabalho tem como foco, conforme se induz do respetivo título, a análise da admissibilidade, como meio de obtenção da prova, a colaboração do coautor do crime com a investigação criminal, auxiliando a recolha de provas, com a atribuição de um prémio por essa conduta.

Já não é nova esta nossa construção ${ }^{1}$ e não estamos sós nesta argumentação aliás, a própria estratégia nacional de combate à corrupção 2020-2024, que se encontra em consulta pública, apresenta-o como sendo um meio de investigação necessário na prevenção e repressão daquela forma de criminalidade ${ }^{2}$.

Como é conhecido quando se fala em investigação criminal, logo como uma espécie de satélite, surgem os princípios da proporcionalidade, necessidade e adequação, como critérios essenciais na legitimação de meios de obtenção da prova que, consequentemente, servem como bússolas que nos guiam no caminho da descoberta da verdade material. No presente trabalho iremos demonstrar que o surgimento desta nova forma de investigação obedece aos referidos e tão importantes princípios. Assim, dividiremos este nosso trabalho em três partes: num primeiro ponto, em respeito ao principio da proporcionalidade, aferiremos para que tipo de criminalidade poderá ser utlizado, melhor quais serão e porquê os seus crimes de catálogo; num

10 nosso anterior trabalho: Conceição, Ana Raquel - O estatuto do arrependido colaborador no dealbar do (ainda) admirável mundo novo - um novo meio de obtenção da prova a tipificar em Portugal. "Julgar Online", abril 2020.[consultado em 2021-04-01]. Disponível na World Wide Web:< http://julgar.pt/o-estatuto-do-arrependido-colaborador-no-dealbar-do-ainda-admiravel-mundo-novo-um-novo-meio-de-obtencao-da-prova-a-tipificar-em-portugal/>.

2 Conforme consta do referido texto: "a complexidade da criminalidade económico-financeira, as dificuldades inerentes à sua investigação, como a necessidade de recorrer a meios de investigação mais eficazes, bem como as suas consequências na vida dos cidadãos, nas finanças do Estado e na economia, justificam que o Estado, enquanto legislador, dispense ou atenue a pena do arguido que denuncie o crime ou colabore ativamente para a descoberta da verdade (...)". [consultado em 2021-04-01], pp. 53-55. Disponível na World Wide Web: <https://www.portugal.gov.pt/downloadficheiros/ficheiro.aspx?v=\%3D\% 3DBQAAAB\%2BLCAAAAAAABAAzNDAxMQAAnRDZFAUAAAA\%3D>. 
segundo momento, em respeito ao princípio da adequação, aferiremos que tipo de colaboração se espera ou exige ao arrependido colaborador e num terceiro e último ponto, apresentaremos os argumentos que outorgam a esta nova forma de investigação o caracter excecional respeitando, desta forma, o princípio da necessidade.

\section{O princípio da proporcionalidade e o arrependido colaborador}

O carácter finalístico do princípio da proporcionalidade prende-se com a manutenção ou alcance do equilíbrio entre o direito fundamental sacrificado e o fim constitucional legítimo. Este, segundo a Convenção Europeia dos Direitos do Homem, assenta principalmente em três pressupostos: a proteção da segurança nacional e pública ou o bem-estar económico do país; a defesa da ordem e a prevenção de crimes ou a defesa dos direitos fundamentais do outro ${ }^{3}$.

O princípio da proporcionalidade impõe uma graduação entre os valores, no sentido em que crimes mais graves, permitirão a utilização de meios mais restritivos e invasivos dos direitos fundamentais dos investigados. 0 princípio do tratamento diversificado da criminalidade mais grave impõe que se tenha de atender ao fim que com que o meio de obtenção da prova visa atingir. É sempre necessária a ponderação da gravidade do ilícito penal investigado face à eficácia. Ou seja, a proporcionalidade não pode ser atendida isoladamente, também como a adequação a necessidade, estes princípios têm todos de ser respeitados cumulativamente pois só assim será legitima a restrição de direitos fundamentais na recolha da prova.

Resta aferir para que tipo de criminalidade poderá ser utilizado o arrependido colaborador.

Hoje, o direito criminal vê-se a braços com um novo tipo de sociedade, uma sociedade aberta, Estados sem fronteiras, que proporcionam uma coexistência de comportamentos diferenciados. Estamos perante uma europeização, uma internacionalização, uma globalização, uma transformação social que se processa à velocidade de uma comunicação global e instantânea e de um processo científico e tecnológico acelerado, radical e imprevisível. Referimo-nos à sociedade do risco de Ulrich Beck, que traduz a ideia de uma sociedade de massas, uma sociedade com ligação e em contacto com qualquer ponto do mundo, dotada de uma veemente e constante evolução das diferentes tecnologias ${ }^{4}$.

Esta sociedade globalizada levou ao aparecimento de novos riscos de dimensão mundial, uma ação humana que poderá ter repercussões em todo o mundo. É um risco de elevada gravidade, sobretudo quando a referida ação humana corresponde à prática de um crime. A globalização trouxe uma repercussão, sem dúvida, de extrema gravidade,

3 Rodríguez Lainz, José Luis - La intervención de las comunicaciones telefónicas. Barcelona: Bosch, 2002, p. 132.

4 Dias, Jorge de Figueiredo - Temas básicos da Doutrina Penal, Sobre os fundamentos da doutrina penal Sobre a Doutrina Geral do Crime, O direito Penal na "Sociedade do Risco". Coimbra: Coimbra Editora, 2001, p. $159 .$. 
a criminalidade internacional organizada. Uma criminalidade que se caracteriza pela sua extrema e rigorosa organização e que afeta uma multiplicidade de Estados.

O nosso legislador no artigo $1^{\circ}$ alínea $\mathrm{m}$ ) do Código de Processo Penal (doravante (PP) define-nos o conceito de criminalidade altamente organizada, estabelecendo que criminalidade altamente organizada são as condutas que integrarem crimes de associação criminosa, tráfico de pessoas, tráfico de armas, tráfico de estupefacientes ou de substâncias psicotrópicas, corrupção, tráfico de influência, participação económica em negócio ou branqueamento. Tal definição não é, em bom rigor, uma definição pois não permite ao intérprete perceber o seu conteúdo, apenas indica quais os crimes que podem merecer tal catalogação.

Na verdade, deveria existir uma definição deste conceito, em prol das características da lei penal que, por força do princípio da legalidade, impõe que esta seja clara, expressa e precisa. Mas de facto não existe, o que pode permitir que se catalogue certo tipo de crime como criminalidade organizada atendendo à sua ratio ${ }^{5}$.

Por tendência, a referida expressão é utilizada para denominar um fenómeno criminal recente e especialmente preocupante pelo seu carácter transnacional e dificuldades investigatórias. A transnacionalidade que a caracteriza impõe que os Estados se unam no seu combate ${ }^{6}$.

Apesar de concordarmos com a argumentação de que não é possível definir o conceito, pois em qualquer das ciências que compõem a ciência global do direito penal o seu uso é polissémico, quanto a nós não restam dúvidas que este conceito tem um móbil processual penal. 0 seu propósito é ver aplicadas certas figuras processuais penais a um conjunto de crimes que hoje em dia têm uma linha condutora comum: são crimes que beneficiaram da evolução tecnológica da nova sociedade e, consequentemente, têm pontos de conexão por todo o mundo, caracterizando-se também por serem, por regra, crimes de colarinho branco, ${ }^{7}$ uma vez que a utilização deste conceito surge predominantemente em instrumentos de natureza internacional no combate e prevenção a este tipo de criminalidade ${ }^{8}$.

5 Tal como refere Augusto Silva Dias: “(...) não pode deixar de causar insegurança jurídica se tivermos presente que a definição do que é criminalidade organizada funciona como pressuposto da aplicação de um regime processual e sancionatório mais severo, consistente em medidas fortemente restritivas de direitos e liberdades". Dias, Augusto Siva - Criminalidade Organizada e combate ao lucro ilícito. " 2 ' Congresso de Investigação Criminal”. Coimbra: Almedina, 2010, pp. 24-47.

6 Neste sentido escreve Francisco Borges: "a discussão em torno da concretização do conceito de "criminalidade organizada” é muito vasta, não se tendo atingido um consenso nesta matéria, nem na dogmática jurídica, nem na criminologia. Na verdade, o termo pode ter muitos significados diferentes, consoante o contexto ou instrumento legislativo em que é utilizado". Borges, Francisco - Criminalidade organizada e cooperação judiciária em matéria penal na União Europeia: traços gerais, "Estudos de Direito e Segurança”. Vol. II, Coimbra: Almedina, 2012, pp. 68-95.

7 Tendencialmente, atribui-se a autoria desta expressão a Edwin Sutherland, no seu discurso de tomada de posse como presidente da American Sociological Society em 1939.

8 Basta atentarmos na própria definição da lei 5/2002, de 11 de janeiro, que expressamente refere, medidas de combate à criminalidade organizada e concretiza essas mesmas medidas. 
Conforme bem realça Hans-Jörg Albrecht, a criminalidade organizada, do ponto de vista empírico, está relacionada com a própria organização societária, o seu fundamento é sociológico e estrutural. Ou seja, é por força das estruturas culturais, sociais, políticas, jurídicas e económicas que a potencialização da criminalidade organizada se constata?.

É a partir desta nova sociedade sem fronteiras, com comunicação em tempo real em qualquer parte do mundo, onde evolução tecnológica é uma constante e onde as estruturas fundamentais de uma sociedade são permeáveis que a criminalidade organizada surge com maior exponencial por força da própria evolução da sociedade. Uma sociedade que cada vez mais se concentra nos mercados financeiros, onde a obtenção do lucro é um pensamento constante, que trespassa todos os seus sectores, e que, associada à evolução científica e tecnológica vai despoletar os crimes associados à criminalidade organizada ${ }^{10}$. 0 fundamento social, político e organizativo é comum ao crime organizado ${ }^{11}$.

Será apenas para estas formas de criminalidade que poderá ser utilizado o arrependido colaborador, respeitando-se, desta feita, o princípio da proporcionalidade.

\section{0 princípio da adequação e o arrependido colaborador}

O princípio da adequação traduz uma ideia de eficácia, ou seja, a restrição dos direitos fundamentais será legitima quando através desta se consiga obter o resultado pretendido.

Transpondo para a investigação criminal, essa razão de eficácia terá de determinar a forte probabilidade de obtenção de meios de prova. Assim, a colaboração investigatória que o arrependido deve realizar deverá determinar a recolha das provas decisivas para a identificação ou a captura dos responsáveis pela prática dos factos ilícitos típicos do crime que se suspeita ter (com)participado. Não se tratará de uma obrigação de resultados mas antes uma obrigação de meios.

Desta feita, a sua colaboração terá de demonstrar ser de grande relevância investigatória e efetivamente ser profícua na obtenção desses elementos de prova, fazendo-se

9 Conforme refere: “(...) no caso da criminalidade organizada a questão é haver condições para a formação de uma organização duradoura e estável e de que forma tal capacidade organização se relaciona com as estruturas sociais." Albrecht, Hans-Jörg - Criminalidade organizada na Europa: perspetiva teorética e empírica. "2² Congresso de Investigação Criminal". Coimbra: Almedina, 2010, pp. 73-99.

10 Conforme refere o autor: "o conceito de criminalidade organizada deve, por isso, ser acrescido de uma análise relativa a mercados negros específicos, nomeadamente o meio e as estruturas de oportunidade, de cujas especificidades se podem extrair conhecimentos relativos à formação de organizações e à racionalização do crime". Idem, p.85.

11 Neste mesmo sentido escreve também Julio Villarejo, quando refere: “(...) todas estas operaciones suelen necessitar de una cierta organización inmersa en lo há venido en denominarse criminalidade organizada, es más, se há afirmado que el blanqueo de capitales es el culmen de la peligrosa criminalidade organizada”. Villarejo, Júlio - La normativa española sobre el blanqueo de capitales. El gafi y las directiva europeas. "Estudos em homenagem ao Prof. Doutor Jorge de Figueiredo Dias". Vol. III, Coimbra: Coimbra Editora, 2010, pp. 253-287. 
cumprir a expressão que tem vindo a constar do texto da lei, recolha das provas decisivas. Uma colaboração total por parte do arguido, ou seja, como acontece na confissão integral e sem reservas, onde o arguido confessa e assume a prática de todos os factos de quem vem acusado ou pronunciado, na "colaboração integral e sem reservas" o arguido tem de retratar à investigação tudo aquilo que à mesma seja útil e que tenha conhecimento direto. Mais do que as suas declarações, a grande eficácia probatória poderá resultar de outros meios de obtenção da prova que podem ser utilizados em função das informações por aquele prestadas. Desta forma, evitar-se-ão situações em que o arguido, ao abrigo do arrependido colaborador, apenas fornece informações sobre parte da investigação ou parte dos arguidos, por alguém (ou alguns) destes o ter(em) aliciado para o efeito. Deverá ser uma "colaboração integral e sem reservas".

Para o referido efeito deverá o arguido renunciar ao seu direito ao silêncio, prestando declarações. Será um meio de obtenção da prova que operará nas fases investigatórias, mas sempre mediante autorização judicial. Nesta outorga judicial, o JIC aferirá do preenchimento dos seus requisitos e ajuizará a aplicação do seu prémio pelo Juiz de julgamento.

Entendemos que, apesar de não ser, em rigor, uma obrigação de resultados, no sentido em que deverá resultar uma acusação ou uma condenação, deverá, todavia, advir algum elemento probatório relevante descrito na lei. Sob pena, face à ausência da tal catalogação, de o arguido poder vir a utilizar esse estatuto apenas porque sabe que é a única forma que terá para vir a beneficiar da atenuação da pena, sem que a sua colaboração seja, de facto e no processo em curso, verdadeiramente eficaz.

Assim, caberá ao Ministério Público aferir da eficácia probatória que poderá resultar do arrependido colaborador, não bastando que se esteja a investigar um dos crimes de catálogo mas, principalmente que nessa investigação a colaboração do arrependido deverá mostra-se essencial, preponderante na recolha da prova.

A título conclusivo o arrependido colaborador, em respeito ao princípio da adequação, terá de trazer ao processo resultados probatórios importantes, devendo sempre colaborar com as autoridades judiciárias ao longo de todo o processo.

\section{0 princípio da necessidade e o arrependido colaborador}

O princípio da necessidade impõe o respeito pela intervenção mínima ou última ratio, característica da lei penal e processual penal. Este princípio vem reforçar a conclusão de que a regra são os direitos e a exceção a sua restrição. Assim, no âmbito da investigação criminal, impõe que a utilização de meios de obtenção de prova deverá obedecer a esta espécie de hierarquia de restrição. Impondo ao intérprete e aplicador da lei, que deverá, sempre, privilegiar a escolha de métodos menos restritivos, só podendo lançar mão do mais restritivos, quando os demais não se mostrem profícuos na recolha de meios de prova. 
Assim, respeitando o princípio da necessidade, deverá existir no processo penal uma grave dificuldade investigatória, onde a referência, por exemplo, à expressão, se houver razões para crer que a diligência é indispensável para a descoberta da verdade ou que a prova seria, de outra forma, impossível ou muito difícil de obter, deve constar. 0 que the outorga um carácter de última ratio ou de intervenção mínima, conforme já referimos antes, em outros trabalhos ${ }^{12}$.

Em respeito à exigência de necessidade o seu regime jurídico deve constar no fim do livro das provas, obrigando à fundamentação judicial no respeito pela estrita necessidade da sua utilização. Cumprindo-se o princípio da necessidade, o arrependido colaborador só poderá ser utilizado quando houver no processo demonstração que já se utilizaram outras meios de recolha de prova sem qualquer resultado probatório, não podendo ser utilizado como meio de investigação primário ou inicial.

O caracter de última ratio do arrependido colaborador impõe-se por força da investigação criminal não assentar, por regra, na colaboração daquele que se investiga assim, a sua admissibilidade terá de pressupor a existência de graves ou crassas dificuldades investigatórias, muito comuns na criminalidade para a qual o arrependido colaborador poderá existir.

O arrependido colaborador é necessariamente arguido no processo penal e, apesar de beneficiar da presunção da inocência e dos seus respetivos corolários, poderá renunciar a tão fundamentais direitos, assumindo os factos, prestando declarações e, consequentemente, auxiliar as autoridades judiciárias na recolha da prova. Importa, acima de tudo, que o faça de forma livre e esclarecida e conhecedor das consequências dessa colaboração. Principalmente que as suas declarações terão valor ultra-ativo ${ }^{13}$ e que beneficiará de uma atenuação especial da pena em sede da aferição da sua culpa, no julgamento.

Será a utilização conjunta e cumulativa da proporcionalidade, adequação e necessidade que fundamentarão a admissibilidade deste novo meio de obtenção da prova.

\section{Conclusão}

As novas exigências de investigação, despoletadas pela nova sociedade que vivenciamos permitiram a erudição e apetrechamento tecnológico dos agentes na prática do crime e, necessariamente, acarretou uma maior necessidade investigatória. Surgindo epistemológica, social e juridicamente a necessidade da criação desta nova figura. Conforme já referimos, e voltamos a realçar, este novo meio de prova só deverá ser admitido, quando estas dificuldades se fazem sentir e, necessariamente, quando em causa esteja a criminalidade organizada altamente evoluída.

12 Expressão utilizada no âmbito das condições de admissibilidade das escutas telefónicas. Sobre tal conceito e conteúdo ver o nosso estudo páginas 80 a 91. Conceição, Ana Raquel - Escutas Telefónicas, Regime Processual Penal. Lisboa: Quid luris, 2009, pp. 80-91.

13 Conforme regime jurídico constante da alínea b) do $n .{ }^{\circ} 4$ do artigo $141^{\circ}$ e n. 3 do $143^{\circ}$ do CPP. 
O estatuto do arrependido colaborador deverá ser encarado como um meio de obtenção da prova que consiste num processo que começa na fase investigatória e se prolonga até ao julgamento. Se em qualquer momento não for cumprido, não produz qualquer tipo de efeito e, consequentemente, o prémio a atribuir pela sua colaboração não se aplicará.

O estatuto de arrependido colaborador, que cremos deverá ser desenhado pelo nosso legislador nacional, deverá passar sempre pelo crivo da autoridade judicial. Deverá ser avaliado pelo Juiz de Instrução Criminal e nunca o Juiz de Julgamento ficará limitado na determinação da medida concreta da pena. 0 que consideramos ser possível como prémio será uma atenuação especial da pena que apenas se repercute no limite abstratamente aplicável.

Há hoje uma clara tendência, em sede de política criminal nacional e estrangeira, no sentido da criação das condições e adoção de medidas destinadas a combater a criminalidade altamente organizada, a qual tem sido responsável por um vasto conjunto de alterações legislativas o que propomos, no seguimento dessas orientações, é a criação de um estatuto de arrependido colaborador. Um estatuto que permitirá dotar a investigação criminal, em especial e a justiça penal em geral, de um meio mais eficaz respondendo às exigências deste (ainda) admirável mundo novo. 